\title{
Oral Health Status, Oral Hygiene Practices, and Factors Affecting Dental Treatment Utilization among Pregnant Women in Dubai
}

\author{
Sosham John Hamda Sultan AlMesmar \\ Dental Services Department, Dubai Health Authority, Dubai, United Arab Emirates
}

\section{Keywords}

Oral health · Oral hygiene - Dental treatment · Pregnancy

\begin{abstract}
Objective: Oral health is an integral part of preventive healthcare for pregnant women. This study aimed to determine the oral health problems and oral hygiene practices and identify the factors affecting dental treatment utilization among a representative population of pregnant women in Dubai. Methods: A cross-sectional study was conducted using data from anonymous structured questionnaires filled by 1,450 pregnant women attending primary health centers across different geographical locations in Dubai. Results: Of the 1,450 women, $97.8 \%$ brushed at least once a day. At least one dental problem during pregnancy was reported by $49.9 \%$, but dental attendance during pregnancy was only $17.4 \%$. Factors associated with dental visits were nationality, previous pregnancy, oral health problems, brushing habits, routine dental visits, and professional advice on oral care. The odds of dental attendance increase for UAE national women by 1.48 , women who had other children before the current pregnancy by 1.35 , those having oral health problems by 1.85 , those who brush more than once a day by 1.51, those who visited the dentist routinely at least once a year by 1.92 , and those who received oral health education by 2.82. The most cited reasons for not going to the dentist were no perceived dental problem (51.8\%) and concerns re-
\end{abstract}

karger@karger.com www.karger.com/dmj

Karger!"
(C) 2021 The Author(s)

Published by S. Karger AG, Basel

This is an Open Access article licensed under the Creative Common Attribution-NonCommercial-4.0 International License (CC BY-NC) (http://www.karger.com/Services/OpenAccessLicense), applicable to the online version of the article only. Usage and distribution for commercial purposes requires written permission. garding the safety of dental treatment during pregnancy (33.9\%). Discussion/Conclusion: In spite of acceptable oral hygiene practices, a significant number of pregnant women (49.9\%) experience dental problems. However, only a few women (17.4\%) visit the dentist during their pregnancy. It is critical to design and implements strategic oral health programs for pregnant women in Dubai.

(C) 2021 The Author(s)

Published by S. Karger AG, Basel

\section{Introduction}

Pregnancy is a physiological condition that brings about various changes in the oral cavity and other body changes. The oral changes include enamel erosion of teeth, caries, gingivitis, periodontitis, loose teeth, and oral pregnancy tumor [1]. Pregnant women may be more at risk for periodontal disease since higher estrogen and progesterone concentrations can induce hyperemia, edema, and bleeding in periodontal tissues [2, 3]. Studies have shown that $30-100 \%$ of pregnant women have gingivitis, the prevalence varying between the populations studied and their characteristics $[2,4]$.

Further, pregnant women are more prone to tooth decay due to the oral cavity's acidic environment, increased consumption of sugary diet, and carelessness toward oral health [1]. Nausea prevents them from observing proper oral hygiene practices. Frequent vomiting episodes in 
pregnancy cause an acidic environment in the oral cavity leading to increased demineralization making teeth prone to caries [5].

There is evidence from various parts of the world that many pregnant women do not visit the dentist [6-8]. Previous studies in the Middle East region show that even though many pregnant women have dental problems, most do not visit a dentist $[9,10]$. They face a significant risk by delaying treatment and consuming over-thecounter medication, which may be unsafe for their pregnancy [11].

Lack of awareness, time, finances, and dissuasion by health-care professionals, including dentists, are some of the various reasons identified as barriers to accessing dental care during pregnancy $[8,12,13]$. American College of Obstetricians and Gynecologists has stated that oral health is an integral part of preventive healthcare for pregnant women and their newborns [14]. The perinatal period is a "teachable moment" for oral healthcare and can potentially affect maternal and infant health. The odds of children having untreated caries doubled when the mother had untreated caries [15].

To our knowledge, there is only one previously published study in the United Arab Emirates (UAE) [16], which reported that $40 \%$ of pregnant women having oral problems did not visit a dentist. However, the patterns, contributing factors, and barriers to attending dental clinics have not been elucidated.

The aim of this study was to identify the oral health status, attitudes, and practices among a representative population of pregnant women in Dubai attending the primary health centers and their reasons for not treating oral health issues during pregnancy through the following questions:

1. How prevalent are dental problems among pregnant women in Dubai?

2. What are the oral hygiene habits and practices of pregnant women in Dubai?

3. What are the factors that may influence the attendance of these patients to access dental treatment?

\section{Materials and Methods}

The population in this study was pregnant women who were 18 years or older in their second or third trimester of pregnancy, who were attending the antenatal clinic in 12 primary health centers of Dubai Health Authority (DHA). Following approval from the Dubai Scientific Research Ethics Committee, the women were approached and asked to complete a self-administered questionnaire available in English and Arabic. The women who participated gave written informed consent for the same.

Oral Health and Dental Treatment in

Pregnant Women in Dubai
A previously developed and validated questionnaire [17] was used with appropriate modifications to adapt to the cultural sensitivity and understanding of the people of Dubai. After the initial construction of the survey questionnaire, 6 dentists reviewed it, and their suggestions for modifications were implemented, and a pilot study was conducted with a cohort of 30 pregnant women. The final questionnaire was made available in English and Arabic and was verified by back-translation.

The questionnaire included sections on demographic information, perceived oral health status, oral hygiene practices, and dental visits. Demographic data, including age, education, employment, parity, and pregnancy status, were collected. The perceived oral health status before and during pregnancy was also obtained regarding any gum problem, loose tooth, and toothache. Women were asked to assess their oral health status and report if they had any dental issues that affected their quality of life. The women were asked about their oral hygiene practices and their visit to the dentist before and during pregnancy. In case of not visiting the dentist, they were asked to select reasons for the same. The reasons included lack of perceived need, concerns regarding the safety of dental treatment during pregnancy, lack of time, dental treatment not being a priority, and being advised against dental care by a family member or health-care professional. They were also asked if any health-care professional had advised them regarding dental care during pregnancy.

The written informed consent was obtained from the participants after explaining the objectives and methodology of the study. The subjects were informed that their participation would be entirely voluntary and that their details would be kept confidential. All participants were handed an envelope containing a consent form with a brief description of the study's purpose and objectives. If they agreed, the participant signed the consent, completed the questionnaire, sealed it in the envelope, and returned it.

Questionnaires were distributed to 1,500 pregnant women in primary health centers of DHA, located in different geographical zones in the Emirate of Dubai. Statistical analysis was done using Statistical Package for Social Sciences software version 20.0 (SPSS Inc, Chicago, IL, USA). The mean and the standard deviation were calculated for continuous variables, frequency, and percentage for categorical variables. As there were a small number of responses in some categories, few of the variables were regrouped to fulfill $\chi^{2}$ test assumptions that no expected frequency should be $<1$ and not $>20 \%$ of the expected frequencies should be $<5$. The $\chi^{2}$ test was used to find the association of dental visit of pregnant women with selected background variables of women, and odds ratio with $95 \%$ confidence interval was used to explain the association of these variables with the dental visit of pregnant women using simple logistic regression analysis. Multiple logistic regression was used to predict independent factors associated with the dental visit of pregnant women. For all statistical interpretations, $p<0.05$ was considered the threshold for statistical significance.

\section{Results}

The response rate from the distributed questionnaires was $96.67 \%$. Out of 1,500 forms distributed, $1,450 \mathrm{com}$ pleted forms were collected, and the data were used to generate descriptive frequency tables.

Dubai Med J 2021;4:320-328 
Table 1. Participant demographics and perceived oral health status

\begin{tabular}{|c|c|c|}
\hline Variable & $N$ & $\%$ \\
\hline \multicolumn{3}{|l|}{ Age, years } \\
\hline $18-25$ & 344 & 23.7 \\
\hline $26-35$ & 944 & 65.1 \\
\hline $36-45$ & 162 & 11.2 \\
\hline \multicolumn{3}{|l|}{ Nationality } \\
\hline UAE & 816 & 56.3 \\
\hline Non-UAE & 634 & 43.7 \\
\hline \multicolumn{3}{|l|}{ Education } \\
\hline No schooling & 21 & 1.4 \\
\hline Middle & 85 & 5.9 \\
\hline High & 426 & 29.4 \\
\hline Diploma & 188 & 13.0 \\
\hline Graduate & 623 & 43.0 \\
\hline Postgraduate & 107 & 7.4 \\
\hline \multicolumn{3}{|l|}{ Employment } \\
\hline Working & 593 & 40.9 \\
\hline Not professionally employed & 857 & 59.1 \\
\hline \multicolumn{3}{|l|}{ Parity } \\
\hline First pregnancy & 445 & 30.7 \\
\hline Has other children & 1,005 & 69.3 \\
\hline \multicolumn{3}{|l|}{ Stage of pregnancy } \\
\hline Second trimester & 869 & 59.9 \\
\hline Third trimester & 581 & 40.1 \\
\hline \multicolumn{3}{|l|}{ Current oral health status } \\
\hline Excellent & 329 & 22.7 \\
\hline Good & 666 & 45.9 \\
\hline Average & 300 & 20.7 \\
\hline Fair & 111 & 7.7 \\
\hline Poor & 44 & 3.0 \\
\hline \multicolumn{3}{|l|}{ Do you have any dental problem } \\
\hline Yes & 723 & 49.86 \\
\hline No & 727 & 50.14 \\
\hline \multicolumn{3}{|l|}{ Bleeding or swollen gums } \\
\hline Yes & 471 & 32.5 \\
\hline No & 979 & 67.5 \\
\hline \multicolumn{3}{|l|}{ One or more teeth felt loose } \\
\hline Yes & 131 & 9.0 \\
\hline No & 1,319 & 91.0 \\
\hline \multicolumn{3}{|c|}{ Sensitivity or pain in one or more teeth } \\
\hline Yes & 427 & 29.4 \\
\hline No & 1,023 & 70.6 \\
\hline \multicolumn{3}{|c|}{$\begin{array}{l}\text { In your current pregnancy, do your oral health problems affect } \\
\text { your eating habits and/or overall health? }\end{array}$} \\
\hline Yes & 300 & 20.7 \\
\hline No & 1,150 & 79.3 \\
\hline
\end{tabular}

The demographic characteristics of the participants, namely age, nationality, education, employment, parity, stage of pregnancy, and perceived oral health status, are seen in Table 1. The participants' age ranged from 18 to 43 years, with a mean age of 29.3 years $(S D \pm 5)$. Around $49.9 \%$ of participants reported having at least one oral health problem during their pregnancy, while $20.7 \%(N=$
Table 2. Frequency distribution of the participants according to oral hygiene habits and dental care visits before and during pregnancy

\begin{tabular}{|c|c|c|}
\hline Characteristics & $N$ & $\%$ \\
\hline \multicolumn{3}{|l|}{ Frequency of toothbrushing } \\
\hline Never & 4 & 0.3 \\
\hline About once a week & 6 & 0.4 \\
\hline A few times a week & 21 & 1.4 \\
\hline Once a day & 297 & 20.5 \\
\hline Twice a day & 901 & 62.1 \\
\hline More than twice a day & 221 & 15.2 \\
\hline \multicolumn{3}{|l|}{ Other oral hygiene aids } \\
\hline Fluoride toothpaste & 1,192 & 82.2 \\
\hline Dental floss & 379 & 26.1 \\
\hline Mouthwash & 599 & 41.3 \\
\hline Sugar-free chewing gum & 419 & 28.9 \\
\hline \multicolumn{3}{|c|}{ Frequency of receipt of routine dental care prior to pregnancy } \\
\hline Never & 247 & 17.0 \\
\hline Less than once per year & 160 & 11.0 \\
\hline Once per year & 327 & 22.6 \\
\hline 2 times a year & 261 & 18.0 \\
\hline$>2$ times per year & 111 & 7.7 \\
\hline Only when experiencing a problem & 344 & 23.7 \\
\hline \multicolumn{3}{|l|}{ Last visit to a dentist } \\
\hline$<6$ months & 401 & 27.7 \\
\hline $6-12$ months & 441 & 30.4 \\
\hline $1-2$ years & 347 & 23.9 \\
\hline $2-5$ years & 102 & 7.0 \\
\hline$>5$ years & 76 & 5.2 \\
\hline Never & 83 & 5.7 \\
\hline \multicolumn{3}{|l|}{ Dental visit in during current pregnancy } \\
\hline Yes & 253 & 17.4 \\
\hline UAE & 169 & 20.7 \\
\hline Non-UAE & 84 & 13.24 \\
\hline No & 1,197 & 82.6 \\
\hline UAE & 647 & 79.3 \\
\hline Non-UAE & 550 & 86.76 \\
\hline \multicolumn{3}{|l|}{ Oral health education received } \\
\hline Yes & 344 & 23.7 \\
\hline No & 1,106 & 76.3 \\
\hline
\end{tabular}

300) reported that their dental problems affected their eating habits and overall health.

Table 2 shows the oral hygiene practices and dental visits reported by the women before and during pregnancy. Around $97.8 \%$ of participants brushed at least once a day, while $77.3 \%$ reported brushing at least twice a day. Around $82.2 \%$ of participants used fluoride-containing toothpaste. While they were not pregnant, $25.7 \%$ participants visited the dentist 2 times or more in a year. Over $22.6 \%$ of participants routinely visited the dentist once a year; $17 \%$ of participants reported never being to a dentist for routine treatment, and $23.7 \%$ went to the dentist only 
Table 3. Association of a visit to a dentist during current pregnancy with selected variables

\begin{tabular}{|c|c|c|c|c|c|}
\hline \multirow[t]{2}{*}{ Characteristics } & \multicolumn{2}{|c|}{$\begin{array}{l}\text { Visit to a dentist during current } \\
\text { pregnancy }\end{array}$} & \multirow[t]{2}{*}{$x^{2}$} & \multirow[t]{2}{*}{$p$ value } & \multirow[t]{2}{*}{$\begin{array}{l}\text { Odds } \\
(95 \% \mathrm{Cl})\end{array}$} \\
\hline & yes & no & & & \\
\hline \multicolumn{6}{|l|}{ Age } \\
\hline $18-25$ & $52(15.1)$ & $292(84.9)$ & \multirow[t]{3}{*}{2.3} & \multirow[t]{3}{*}{0.317} & - \\
\hline $26-35$ & $175(18.5)$ & $769(81.5)$ & & & - \\
\hline $36-45$ & $26(16)$ & $136(84)$ & & & - \\
\hline \multicolumn{6}{|l|}{ Nationality } \\
\hline UAE & $169(20.7)$ & $647(79.3)$ & \multirow[t]{2}{*}{13.79} & \multirow[t]{2}{*}{$<0.01$} & $1.71(1.29-2.28)$ \\
\hline Non-UAE & $84(13.2)$ & $550(86.8)$ & & & 1 \\
\hline \multicolumn{6}{|l|}{ Education } \\
\hline Up to high school graduate & $94(17.7)$ & $438(82.3)$ & \multirow[t]{3}{*}{0.58} & \multirow[t]{3}{*}{0.749} & - \\
\hline Diploma & $36(19.1)$ & $152(80.9)$ & & & - \\
\hline Bachelors/masters degree & $123(16.8)$ & $607(83.2)$ & & & - \\
\hline \multicolumn{6}{|l|}{ Professionally employed } \\
\hline Yes & $113(19.1)$ & $480(80.9)$ & \multirow[t]{2}{*}{1.8} & \multirow[t]{2}{*}{0.180} & - \\
\hline No & $140(16.3)$ & $717(83.7)$ & & & - \\
\hline \multicolumn{6}{|l|}{ Parity } \\
\hline Multi & $189(18.8)$ & $816(81.2)$ & \multirow[t]{2}{*}{4.19} & \multirow[t]{2}{*}{0.041} & $1.38(1.01-1.88)$ \\
\hline Primi & $64(14.4)$ & $381(85.6)$ & & & 1 \\
\hline \multicolumn{6}{|l|}{ Reported current oral health status } \\
\hline Excellent/good & $164(16.5)$ & $831(83.5)$ & \multirow[t]{3}{*}{2.97} & \multirow[t]{3}{*}{0.226} & - \\
\hline Average & $55(18.3)$ & $245(81.7)$ & & & - \\
\hline Fair/poor & $34(21.9)$ & $121(78.1)$ & & & - \\
\hline \multicolumn{6}{|l|}{ Dental problem during pregnancy } \\
\hline Yes & $158(21.9)$ & $565(78.1)$ & \multirow[t]{2}{*}{19.43} & \multirow[t]{2}{*}{$<0.01$} & $1.86(1.41-2.46)$ \\
\hline No & $95(13.1)$ & $632(86.9)$ & & & 1 \\
\hline \multicolumn{6}{|l|}{ Brushing habit } \\
\hline Up to once a day & $38(11.6)$ & $290(88.4)$ & 17.41 & $<0.01$ & 1 \\
\hline 2 times a day & $159(17.6)$ & $742(82.4)$ & & & $1.58(1.12-2.24)$ \\
\hline$>2$ times a day & $56(25.3)$ & $165(74.7)$ & & & $2.59(1.65-4.08)$ \\
\hline Oral hygiene products use & & & & & \\
\hline Yes & $239(17.8)$ & $1,106(82.2)$ & 1.33 & 0.249 & - \\
\hline No & $14(13.3)$ & $91(86.7)$ & & & - \\
\hline Frequency of receipt of routine & re prior to $\mathrm{p}$ & ancy & & & \\
\hline Never/rare & $88(11.7)$ & $663(88.3)$ & 35.52 & $<0.01$ & 1 \\
\hline One or more times a year & $165(23.6)$ & $534(76.4)$ & & & $2.33(1.76-3.09)$ \\
\hline Oral health education received & & & & & \\
\hline Yes & $100(29.1)$ & $244(70.9)$ & 42.29 & $<0.01$ & $2.55(1.91-3.41)$ \\
\hline No & $153(13.8)$ & $953(86.2)$ & & & 1 \\
\hline
\end{tabular}

to treat a problem. Since becoming pregnant, $17.4 \%$ of women visited a dentist, while $82.6 \%$ did not make any visit to the dentist. Women of UAE nationality showed a slightly higher attendance for dental treatment than that of non-nationals. Around $23.7 \%$ of participants had received some information about oral healthcare during pregnancy from a health-care professional.

Table 3 shows the distribution of the mothers' profile in the group who visited the dentist compared with those who did not. The factors associated with the mothers' vis-

Oral Health and Dental Treatment in

Pregnant Women in Dubai it to the dentist were identified by simple logistic regression analysis. Among the women of UAE nationality, $20.7 \%$ visited the dental clinic during pregnancy compared to $13.2 \%$ of non-UAE women. The $\chi^{2}$ test $(p<0.01)$ shows that the dental visit of pregnant women is significantly associated with the nationality of the women. Women from UAE have more chance to visit a dentist during pregnancy with an odds of 1.71 than non-UAE women. Regarding parity, $18.8 \%$ of women who have children previously visited the dentist compared to $14.4 \%$ 
Table 4. Independent factors associated with the dental visit of pregnant women by multiple logistic regression

\begin{tabular}{|c|c|c|c|c|}
\hline Characteristics & B & SE & $p$ value & Odds $(95 \% \mathrm{Cl})$ \\
\hline \multicolumn{5}{|l|}{ Nationality (non-UAE ${ }^{\circledR}$ ) } \\
\hline UAE & 0.39 & 0.16 & 0.013 & $1.48(1.09-2.02)$ \\
\hline \multicolumn{5}{|l|}{ Parity $\left(\right.$ primi ${ }^{\circledR}$ ) } \\
\hline Multi & 0.30 & 0.16 & 0.068 & $1.35(0.98-1.87)$ \\
\hline \multicolumn{5}{|c|}{ Dental problem during pregnancy $\left(\mathrm{no}^{\circledR}\right)$} \\
\hline Yes & 0.61 & 0.17 & 0.000 & $1.85(1.32-2.59)$ \\
\hline \multicolumn{5}{|c|}{ Brushing habit (up to once a day ${ }^{\circledR}$ ) } \\
\hline 2 times a day & 0.41 & 0.20 & 0.042 & $1.51(1.02-2.24)$ \\
\hline$>2$ times a day & 0.73 & 0.25 & 0.003 & $2.07(1.28-3.36)$ \\
\hline \multicolumn{5}{|c|}{ Previous visit to dentist (never/rare ${ }^{\circledR}$ ) } \\
\hline Once or more a year & 0.65 & 0.15 & 0.000 & $1.92(1.42-2.59)$ \\
\hline \multicolumn{5}{|c|}{ Oral health education received (no ${ }^{\circledR}$ ) } \\
\hline Yes & 1.04 & 0.16 & 0.000 & $2.82(2.07-3.82)$ \\
\hline
\end{tabular}

$\mathrm{SE}$, standard error; $\mathrm{Cl}$, confidence interval. of women who were pregnant with their first child. Therefore, the dental visit of pregnant women is significantly associated with parity $(p=0.041)$. Women who had children before the current pregnancy had more chance to visit the dentist than primi women, with an odds of 1.38. There is a significant association $(p<0.01)$ between women who reported experiencing a dental problem during pregnancy and their dental visit. Women who reported experiencing a dental issue have more chance to visit a dentist during pregnancy with an odds of 1.86 as than those who did not report any dental problem. There is a significant association $(p<0.01)$ between the brushing habit of women and their dental visit. Women who brushed 2 times a day or more had more chance to visit the dentist than those who brushed up to once a day with an odds of 1.58 and 2.59, respectively. Frequency of receipt of routine dental care before pregnancy is significantly associated $(p<0.01)$ with dental visits during pregnancy. Those women who routinely visited the dentist at least once a year have more chance to visit the dentist than others, with an odds of 2.33 . There is a significant association $(p<0.01)$ between receiving oral health education during pregnancy and dental visit. Women who had received oral health education had more chance of visiting the dentist than others, with an odds of 2.55.

Table 4 shows the independent factors associated with the dental visit of pregnant women by multiple logistic regression analysis. A dental visit during pregnancy was taken as a dependent variable, and variables that have $p<$ 0.15 at bivariate analysis were taken as independent variables. The independent variables used for multiple logistic regression are nationality, parity, dental problem during pregnancy, brushing habit, routine dental visit, and oral health education received during pregnancy. The independent factors elicited from the multiple logistic regression are nationality, parity, oral health problems, brushing habits, routine dental visit, and oral health education received. The dental visit of pregnant women is significantly associated with nationality of the women $(p=0.013)$. UAE national women have more chance to visit a dentist during pregnancy with an odds of 1.48 than non-UAE women. The dental visit of pregnant women is significantly associated with parity $(p=0.068)$. Women who had children previously had more chance to visit the dentist than primi women, with an odds of 1.35 . There is a significant association $(p<0.01)$ between women who reported experiencing a dental problem during pregnancy and their dental visit. Women who reported experiencing a dental issue have more chance to visit a dentist during pregnancy with an odds of 1.85 than those who did not report any dental problem. There is a significant association ( $p=0.042$ ) between the brushing habit of women and their dental visit. Women who brushed 2 times a day had more chance to visit the dentist than those who brushed up to once a day with an odds of 1.51. Frequency of receipt of routine dental care prior to pregnancy is significantly associated $(p<0.01)$ with dental visits during pregnancy. Those women who routinely visited the dentist at least once a year have more chance to visit the dentist than others, with an odds of 1.92. There is a significant association $(p<0.01)$ between receiving oral health education during pregnancy and dental visit. Women who had received oral health education had more chance of visiting the dentist than the others, with an odds of 2.82 .

Figure 1 shows the distribution of the study population according to the barriers to dental visits during pregnan- 


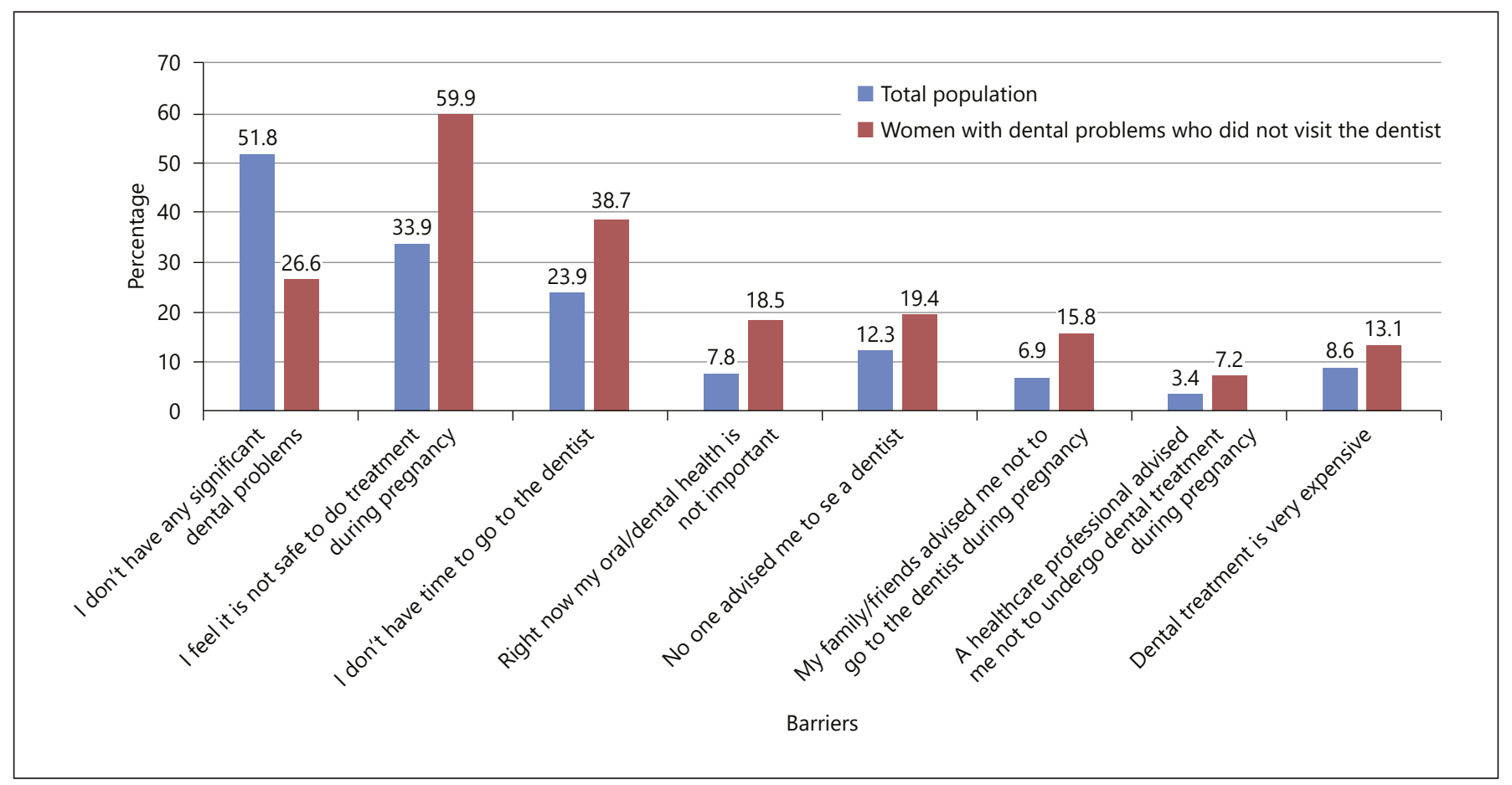

Fig. 1. Bar graph showing percentage distribution of the sample according to barriers for visiting the dentist.

cy. In general, the most cited reason for not going to a dentist was no perceived dental problem (51.8\%). Around $33.9 \%$ of participants felt it was not safe to undergo dental treatment during pregnancy. Among the 300 women who reported having problems that affect their daily routine, $222(74 \%)$ did not visit the dentist. For these women, the most cited reason for nonattendance was that it was unsafe to get dental treatment during pregnancy (59.9\%, $n=133)$, followed by lack of time to go to a dentist (38.7\%, $n=86)$.

\section{Discussion}

The World Health Organization Global Oral Health Policy emphasizes that oral health is a determining factor for the quality of life [18]. Dubai is the most populous city and is one of the 7 emirates in the UAE [19]. Each emirate governs its health-care standards according to its internal laws. DHA oversees the health sector of the Emirate of Dubai, providing services through primary health centers spread throughout the emirate.

The Oral and Dental care, Program 5 of the Dubai Health Strategy 2016-2021 seeks to improve oral health outcomes and ensure that all individuals have access to high-quality treatments and effective prevention programs for dental care [20]. Pregnant women are part of the population whose oral health is frequently neglected [14]. Therefore, to develop and implement effective programs to improve the oral health of pregnant women in Dubai, it is essential to assess the current practices and attitudes to seeking dental treatment, specifically among the residents of Dubai. To our knowledge, this study, for the first time, aimed to identify the oral health problems, practices, attitudes of pregnant women across Dubai, factors affecting their dental service utilization, and barriers to the same.

\section{Oral Health Status and Practices}

Toothbrushing habits of pregnant women in Dubai were acceptable, and many used fluoridated toothpaste. This finding is comparable to a previous study on the UAE population [16] and better than the findings from Kuwait [21]. However, very few women flossed regularly, which showed a lack of understanding of the importance of flossing as part of oral hygiene. Almost half the women reported having a dental problem, the most common one being "gum problems". Around 20\% reported having dental problems severe enough to affect their daily life and were more likely to visit the dentist, as can be ex- 
pected. Employment and the education level did not have a significant influence on the dental visit. This is similar to findings from other studies $[6,8]$. Perceived oral health status was also not a significant predictor in this study, similar to a study in Kuwait [21] and Malaysia [8].

\section{Dental Visits of Pregnant Women}

When they were not pregnant, almost half the women frequented the dentist at least once a year. But since becoming pregnant, out of the total number of pregnant women surveyed, only $17.4 \%$ had been to a dentist. This number is far less than the previous study of the UAE population [16], which reported that more than half the women had visited the dentist during their pregnancy but is similar to other reported studies in the region. In Riyadh, 22\% of pregnant women [9] and $14 \%$ of Turkish women [10] had been to a dentist. Further, it was seen that regardless of dental problems, pregnant women who otherwise maintained regular visits to a dentist were more likely to visit the dentist during pregnancy. Some other studies also report similar findings $[9,17,22]$, which indicates that routine dental care is a strong predictor of whether a woman visits the dentist during her pregnancy.

\section{Barriers to Accessing Dental Care during Pregnancy}

Several barriers to accessing dental care during pregnancy have been reported previously. In our study, the lack of perceived need, followed by the fear of the safety of dental treatment, was the most reported one. Financial barriers did not pose a significant barrier for dental treatment as in Dubai. This may be so because all UAE nationals have full financial coverage for their dental treatment, and most of the non-UAE expatriates have some dental insurance coverage. This finding is similar to other studies in the Middle East region $[9,10]$. However, in contrast, some studies in other parts of the world have shown financial barriers to be a significant contributing factor $[6$, 12]. The financial coverage for dental treatment for UAE nationals is probably the reason why nationality was seen to be a significant predictor in a dental visit during pregnancy.

A key finding from this study is that among the 300 women who reported having problems that affect their daily routine, 222 did not visit the dentist. The main barrier reported by this group of women was fear of the safety of dental treatment. This implies that even though they had dental problems, the women did not perceive oral healthcare as a pressing need and would probably delay the dental visit to post their delivery. This is a concern to be addressed as these women may be experiencing a quality of life that is less than optimum. Untreated dental problems may lead to irreparable damage to the periodontium and tooth structures and may have adverse effects on the child $[23,24]$. This lack of urgency to seek dental treatment is enhanced by the fact that less than a quarter $(23.7 \%)$ of the women received any counseling or advice about their oral health during pregnancy. This seems to be a global pattern, as in a study across ten states of the USA, it was noted that $59 \%$ of pregnant women did not receive oral health counseling [25], and in Sydney, only $10 \%$ received any oral health promotion [26]. A significant finding is that women who received oral health education were more likely to visit the dentist during pregnancy. This is consistent with the findings of some other studies $[8,12]$.

Dental treatment during pregnancy is safe and should not be delayed [27]. To correct the misconception about the fear of dental treatment in pregnancy, the dental professional, along with other health-care providers like the obstetrician, gynecologist, and midwives, must work together to pass on important messages about the importance of dental care and good oral hygiene. The provision of oral health education to all antenatal mothers should be made mandatory, and the need for routine dental visits both before and during pregnancy must be emphasized.

\section{Limitations and Strengths}

The limitations of the study include the possible bias associated with self-reported information obtained from the self-administered questionnaire. A clinical examination was not conducted to confirm the self-reported oral health problems, and so, the prevalence of problems might be even higher. This study's strength is that it focuses on the emirate of Dubai, with the sample population spread across the primary health centers covering the various geographical zones. Therefore, based on this study's results, targeted efforts to promote oral healthcare and its awareness during pregnancy can be implemented through Emirate-wide policies and strategies.

\section{Conclusion}

A significant number of pregnant women $(49.9 \%)$ in Dubai have oral health problems. Toothbrushing habits of pregnant women in Dubai were acceptable, and many used fluoridated toothpaste. However, dental treatment 
utilization during pregnancy is low. Fear of the safety of dental treatment and lack of perceived need were the significant reasons causing women to avoid visiting the dentist. Routine dental visits, oral health education, brushing habits, oral health problems, nationality, and parity were significant predictors for a dental visit during pregnancy. There is a need for formulating and implementing targeted oral health programs for pregnant women.

\section{Acknowledgement}

The authors would like to thank Dr. Nadia Saleh and Dr. Khaled Farghali for reviewing the study proposal. A special note of thanks to Ms. Hend Mohd Sultan and the team of antenatal nurses of DHA for their support.

\section{Statement of Ethics}

This study was approved by the Dubai Scientific Research Ethics Committee (DSREC-02/2018-03), and written informed consent was obtained from all the participants.

\section{Conflict of Interest Statement}

The authors have no conflicts of interest to declare.

\section{Funding Sources}

This research did not receive any specific grant from funding agencies in the public, commercial, or not-for-profit sectors.

\section{Author Contributions}

S.J. contributed to conceptualization, methodology, investigation, data curation, writing-original draft preparation, and visualization. H.S.A. contributed to supervision, writing-reviewing, and editing.

\section{Data Availability Statement}

The research raw data are not publicly available due to ethical reasons. The data are available with the corresponding author and can be made available upon receiving a formal and reasonable request.

\section{References}

1 Silk H, Douglass AB, Douglass JM, Silk L. Oral health during pregnancy. Am Fam Physician. 2008 Apr;77(8):1139-44.

2 Laine MA. Effect of pregnancy on periodontal and dental health. Acta Odontol Scand. 2002 Oct;60(5):257-64.

3 Taani DQ, Habashneh R, Hammad MM, Batieha $\mathrm{A}$. The periodontal status of pregnant women and its relationship with socio-demographic and clinical variables. J Oral Rehabil. 2003 Apr;30(4):440-5.

4 Wu M, Chen SW, Jiang SY. Relationship between gingival inflammation and pregnancy. Mediators Inflamm. 2015;2015:623427.

5 Lazarchik DA, Frazier KB. Dental erosion and acid reflux disease: an overview. Gen Dent. 2009 Mar-Apr;57:151-8.

6 Dinas K, Achyropoulos V, Hatzipantelis E, Mavromatidis G, Zepiridis L, Theodoridis T, et al. Pregnancy and oral health: utilisation of dental services during pregnancy in northern Greece. Acta Obstet Gynecol Scand. 2007; 86(8):938-44.

7 Marchi KS, Fisher-Owens SA, Weintraub JA, Yu Z, Braveman PA. Most pregnant women in California do not receive dental care: Findings from a population-based study. Public Health Rep. 2010 Nov-Dec;125:831-42.

8 Saddki N, Yusoff A, Hwang YL. Factors associated with dental visit and barriers to utilisation of oral health care services in a sample of antenatal mothers in Hospital Universiti
Sains Malaysia. BMC Public Health. 2010 Feb; 10:75.

9 Al-Swuailem AS, Al-Jamal FS, Helmi MF. Treatment perception and utilization of dental services during pregnancy among sampled women in Riyadh, Saudi Arabia. Saudi J Dent Res. 2014 July;5(2):123-9.

10 Özen B, Özer L, Başak F, Altun C, Açıkel C. Turkish women's self-reported knowledge and behavior towards oral health during pregnancy. Med Princ Pract. 2012;21(4):31822.

11 Servey J, Chang J. Over-the-counter medications in pregnancy. Am Fam Physician. 2014 Oct;90(8):548-55.

12 Al Habashneh R, Guthmiller JM, Levy S, Johnson GK, Squier C, Dawson DV, et al. Factors related to utilization of dental services during pregnancy. J Clin Periodontol. 2005 Jul;32(7):815-21.

13 Keirse MJ, Plutzer K. Women's attitudes to and perceptions of oral health and dental care during pregnancy. J Perinat Med. 2010;38(1): 3-8.

14 American College of Obstetricians; Committee on Health Care for Underserved Women. Committee opinion No. 569: oral health care during pregnancy and through the lifespan. Obstet Gynecol. 2013 Aug; 122(2):417-22.

15 Da Silva Bastos VA, Freitas-Fernandes LB, Fidalgo TKS, Martins C, Mattos CT, De Souza
IPR, et al. Mother-to-child transmission of streptococcus mutans: a systematic review and meta-analysis. J Dent. 2015 Feb;43(2): 181-91.

16 Hashim R. Self-reported oral health, oral hygiene habits and dental service utilization among pregnant women in United Arab Emirates. Int J Dent Hyg. 2012 May;10(2): 142-6.

17 Boggess KA, Urlaub DM, Massey KE, Moos MK, Matheson MB, Lorenz C. Oral hygiene practices and dental service utilization among pregnant women: an in vitro study. J Am Dent Assoc. 2010 May;141(5):553-61.

18 Petersen PE. Global policy for improvement of oral health in the 21st century: implications to oral health research of World Health Assembly 2007, World Health Organization. Community Dent Oral Epidemiol. 2009 Feb; 37(1):1-8.

19 Dubai Statistics Center; Government of Dubai. Population bulletin. 2015. Retrieved from Dubai Statistics Center. Available from: https: //www.dsc.gov.ae/Publication/Population $\% 20$ Bulletin $\% 20$ Emirate $\% 20$ of\% 20 Dubai\%202015.pdf.

20 Dubai Health Authority. Dubai health strategy 2016-2021: towards a healthier and happier community. 2016. Retrieved from Dubai Health Authority. Available from: https:// www.dha.gov.ae/Documents/Dubai Health_Strategy_2016-2021_En.pdf. 
21 Honkala S, Al-Ansari J. Self-reported oral health, oral hygiene habits, and dental attendance of pregnant women in Kuwait. J Clin Periodontol. 2005 Jul;32(7):809-14.

22 Fadavi S, Sevandal MC, Koerber A, Punwani I. Survey of oral health knowledge and behavior of pregnant minority adolescents. Pediatr Dent. 2009 Sep-Oct;31:405-8.

23 Cruz SS, Costa MC, Gomes-Filho IS, Rezende EJ, Barreto ML, Dos Santos CA, et al. Contribution of periodontal disease in pregnant women as a risk factor for low birth weight. Community Dent Oral Epidemiol. 2009 Dec; 37(6):527-33
24 Ercan E, Eratalay K, Deren O, Gur D, Ozyun$\mathrm{cu} \mathrm{O}$, Altun B, et al. Evaluation of periodontal pathogens in amniotic fluid and the role of periodontal disease in pre-term birth and low birth weight. Acta Odontol Scand. 2013 MayJul;71:553-9.

25 Hwang SS, Smith VC, McCormick MC, Barfield WD. Racial/ethnic disparities in maternal oral health experiences in 10 states, pregnancy risk assessment monitoring system, 2004-2006. Matern Child Health J. 2011 Aug;15(6):722-9.
26 George A, Johnson M, Blinkhorn A, Ajwani S, Ellis S, Bhole S. Views of pregnant women in South Western Sydney towards dental care and an oral-health program initiated by midwives. Health Promot J Austr. 2013 Dec; 24(3):178-84.

27 Hagai A, Diav-Citrin O, Shechtman S, Ornoy A. Pregnancy outcome after in utero exposure to local anesthetics as part of dental treatment: a prospective comparative cohort study. J Am Dent Assoc. 2015 Aug;146(8): $572-80$ 